\title{
Central and autonomic system signs with in utero drug exposure
}

\author{
H S Bada, C R Bauer, S Shankaran, B Lester, L L Wright, A Das, K Poole, V L Smeriglio, \\ L P Finnegan, P L Maza
}

Arch Dis Child Fetal Neonatal Ed 2002;87:F106-F112

See end of article for authors' affiliations

....................

Correspondence to:

Dr H S Bada, 800 Rose

Street, Room MS473,

Kexington, $\mathrm{KY}$

40536-0198, USA;

hbada@uky.edu

Accepted 4 April 2002

\begin{abstract}
Aims: To determine risk for central nervous system/autonomic nervous system (CNS/ANS) signs following in utero cocaine and opiate exposure.

Methods: A multisite study was designed to determine outcomes of in utero cocaine and opiate exposure. A total of 11811 maternal/infant dyads were enrolled. Drug exposed (EXP) infants were identified by maternal self report of cocaine or opiate use or by meconium testing. Of $1185 \mathrm{EXP}$, meconium analysis confirmed exposure in 717 to cocaine (CO) only, 100 to opiates (OP), and 92 to opiates plus cocaine $(\mathrm{OP}+\mathrm{CO})$; 276 had insufficient or no meconium to confirm maternal self report. Negative exposure history was confirmed in 7442 by meconium analysis and unconfirmed in 3184 . Examiners masked to exposure status, assessed each enrolled infant. Using generalised estimating equations, adjusted odds ratios (OR) and $95 \%$ confidence intervals $(\mathrm{Cl})$ were estimated for manifesting a constellation of CNS/ANS outcomes and for each sign associated with cocaine and opiate exposure.

Results: Prevalence of CNS/ANS signs was low in $\mathrm{CO}$, and highest in $\mathrm{OP}+\mathrm{CO}$. Signs were significantly related to one another. After controlling for confounders, $\mathrm{CO}$ was associated with increased risk of manifesting a constellation of CNS/ANS outcomes, OR (95\% CI): 1.7 (1.2 to 2.2), independent of OP effect, OR (95\% Cl): 2.8 (2.1 to 3.7). OP+CO had additive effects, OR (95\% Cl): 4.8 (2.9 to 7.9). Smoking also increased the risk for the constellation of CNS/ANS signs, OR (95\% Cl) of 1.3 (1.04 to 1.55) and 1.4 (1.2 to 1.6), respectively, for use of less than half a pack per day and half a pack per day or more. Conclusion: Cocaine or opiate exposure increases the risk for manifesting a constellation of CNS/ANS outcomes.
\end{abstract}

As part of a multisite study, the Maternal Lifestyle Study (MLS), to evaluate acute and long term effects of in utero cocaine and or opiate exposure on infant outcomes, ${ }^{28}$ we estimated the prevalence of CNS/ANS signs in neonates born to mothers who used cocaine/opiates during pregnancy. A priori, we addressed the hypothesis that compared to non-exposed infants, the prevalence of CNS/ANS signs would be increased in infants exposed to cocaine or opiates in utero. We further hypothesised that there would be no difference in the prevalence of these signs between cocaine and opiate exposure.

\section{METHODS}

The study involved a multisite evaluation of effects of maternal lifestyle choices during pregnancy on their infants' acute and long term developmental outcomes in four centres of the National Institute of Child Health and Human Development Neonatal Research Network. These sites included Brown University (Providence, RI), University of Miami (Miami, FL), The University of Tennessee, Memphis (Memphis, TN), and Wayne State University (Detroit, MI). The Biostatistics Coordinating Center at George Washington University, Washington, DC, provided data management, research coordination, and statistical design and analysis, and later was succeeded by the Research Triangle Institute (Research Triangle Park, NC). A detailed description of this study has been reported previously. ${ }^{28}$

Abbreviations: ANS, autonomic nervous system; CNS, central nervous system; $\mathrm{CO}$, cocaine; EMIT, enzyme multiplied immunoassay technique; EXP, exposed; GA, gestational age; GC/MS, gas chromatography/mass spectroscopy; GEE, generalised estimating equations; MLS, Maternal Lifestyle Study; NON, non-exposed; OP, opiate abnormalities were severe as detected clinically, radiologically, or by electroencephalographic and physiological studies. ${ }^{22-27}$

ceases while neonatal drug metabolism and excretion continue, to treat heroin addiction, especially in pregr marily cocaine ${ }^{14} 15$ Madden et al observed no signs of teratoger exposed controls. Studies by Oro and Dixon ${ }^{20}$ and by Napiorkowski and colleagues ${ }^{21}$ revealed that cocaine exposed infants exhibited more stress behaviour, increased tone, motor activity, jerky movements, tremors, and more CNS signs than nonexposed controls. In other reports, CNS and other neurological 
Table 1 Characteristics of mothers and infants

\begin{tabular}{|c|c|c|c|c|c|c|}
\hline Characteristics & $\begin{array}{l}\text { Unconfirmed } \\
\mathrm{n}=3184 \\
\%\end{array}$ & $\begin{array}{l}\text { NON } \\
n=7442 \\
\%\end{array}$ & $\begin{array}{l}\operatorname{EXP} \\
n=1185 \\
\%\end{array}$ & $\begin{array}{l}\mathrm{CO} \\
\mathrm{n}=717 \\
\%\end{array}$ & $\begin{array}{l}\text { OP } \\
n=100 \\
\%\end{array}$ & $\begin{array}{l}\mathrm{OP}+\mathrm{CO} \\
\mathrm{n}=92 \\
\%\end{array}$ \\
\hline Black & 48 & 48 & $76 *$ & 81 * & 47 & 59 \\
\hline Married & 41 & 40 & $13^{*}$ & $10 *$ & 34 & $12^{*}$ \\
\hline Medicaid & 62 & 62 & $87^{*}$ & $86 *$ & 66 & $89 *$ \\
\hline Education $\leqslant 12$ years & 72 & 69 & $84^{*}$ & $86^{*}$ & 73 & 80 \\
\hline Prenatal care: inadequate & 14 & 12 & $45^{*}$ & $50 *$ & 15 & 41 * \\
\hline Sexually transmitted diseases & 14 & 13 & $28 *$ & $29 *$ & $23^{*}$ & 16 \\
\hline Marijuana use & 4 & 5 & $37^{*}$ & $39 *$ & 9 & $38 *$ \\
\hline \multicolumn{7}{|l|}{ Smoking } \\
\hline No & 82 & 82 & $23 *$ & 21 * & $54^{*}$ & $13^{*}$ \\
\hline$<1 / 2$ pack/day & 7 & 7 & 27 & 29 & 9 & 21 \\
\hline$\geqslant 1 / 2$ pack/day & 11 & 11 & 50 & 50 & 37 & 66 \\
\hline \multicolumn{7}{|l|}{ Alcohol } \\
\hline None & 71 & 69 & 31 * & $27 *$ & 61 & $45^{*}$ \\
\hline$<1$ drink/month & 22 & 24 & 20 & 19 & 27 & 8 \\
\hline 1-3 drinks/month & 4 & 4 & 16 & 18 & 4 & 16 \\
\hline$\geqslant 1$ drink/week & 3 & 3 & 34 & 36 & 8 & 32 \\
\hline \multicolumn{7}{|l|}{ Infants' GA } \\
\hline $25-32 w k$ & 10 & 8 & 16 & 15 & 10 & 16 \\
\hline $33-36 w k$ & 14 & 14 & 26 & 28 & 22 & 26 \\
\hline $37-42$ wk & 75 & 77 & $58^{*}$ & $59 *$ & 68 & $58 *$ \\
\hline \multicolumn{7}{|l|}{ Body weight } \\
\hline $501-1500 \mathrm{~g}$ & 8 & 5 & 10 & 10 & 10 & 16 \\
\hline $1501-2500 \mathrm{~g}$ & 16 & 16 & 33 & 36 & 20 & 37 \\
\hline$>2500 \mathrm{~g}$ & 76 & 79 & $57^{*}$ & $55^{*}$ & 70 & $47^{*}$ \\
\hline
\end{tabular}

Enrolment was carried out between May 1993 and May 1995 with the following eligibility criteria: (1) inborn; (2) birth weight $>500 \mathrm{~g}$; (3) singleton gestation; (4) best obstetrical estimate of gestational age (GA) $<43$ weeks; (5) not unlikely to survive; (6) birth within the stipulated sampling time frame specific to each clinical site as determined by each site's number of live births and a priori estimated prevalence of drug use among pregnant women. Maternal exclusion criteria were age $<18$ years, institutionalised for mental retardation or emotional disorder, or diagnosis of psychosis. After informed consent, mothers were interviewed for a brief history on illicit drug, cigarette, and alcohol use during the 12 months prior to birth. If a mother smoked during pregnancy, she was asked whether she smoked less than half a pack of cigarettes per day, or half a pack or more per day. If she drank alcohol, she was asked if she drank $<$ l drink/month, 1-3 drinks/month, or $\geqslant 1$ drink/week, and whether she had $>5$ drinks at any one time (binge).

Infants were assessed by a research nurse masked to the infant's drug exposure status. Research nurses involved in the study had training and certification on procedures, assessment, and definitions of variables according to the MLS Manual of Operations. Vital signs and growth measurements were obtained, and GA by New Ballard ${ }^{29}$ examination determined with physical examination, and evaluation for presence of CNS/ANS signs..$^{19-23} 3031$ CNS signs assessed included abnormalities (microphthalmia, encephalocoele, meningomyelocoele, skull defect), disturbances in state, activity, or tone (hyperactivity, hyperalertness, hypertonicity, hypotonicity, jitteriness/tremors, high pitched cry, weak cry, abnormal posture, fisting, difficult to console, difficult to arouse, irritability, lethargy), and eye signs (notable strabismus, nystagmus, and sunset eye sign). ANS signs evaluated included sweating, sneezing, hiccoughing, mottling, bradycardia, tachycardia, poor suck, excessive suck, nasal stuffiness, hyperthermia, and hypothermia.

Meconium was also collected and specimens were centrally assayed at El Sohly Laboratories, Oxford, MS. Each specimen received was analysed for presence of cocaine and opiates by enzyme multiplied immunoassay technique (EMIT), with subsequent confirmation of positive samples using gas chromatography/mass spectroscopy (GC/MS). ${ }^{32}$
Non-exposed (NON) and exposed (EXP) groups were defined a priori during the study design. NON infants were those whose mother denied both cocaine and opiate use during pregnancy, confirmed by a negative EMIT screen. Infants were considered EXP either by maternal self report of cocaine and/or opiate use, or by meconium results that were positive for cocaine or opiates by GC/MS. Infants were considered exposed to cocaine (CO) only, opiate (OP) only, and to both drugs $(\mathrm{OP}+\mathrm{CO})$ if exposure was confirmed by GC/MS meconium analysis.

Statistical methods included estimation of prevalence of each of the CNS/ANS signs in NON, EXP, CO, OP, and OP+CO groups. The EXP was first compared to NON, and odds ratios (OR) and 95\% confidence intervals (CI) for each of the CNS/ANS signs determined. Signs that were significant at $\mathrm{p}<0.05$ by univariate analysis were selected as the CNS/ANS outcomes for subsequent multivariate analysis.

In the multivariate analysis, we chose not to fit separate regression models for each CNS/ANS sign or outcome, as this was deemed vulnerable to problems of multiple comparisons, therefore increasing the type I error to unacceptable levels. Instead, we adopted a multivariate modelling approach wherein we simultaneously modelled all CNS/ANS outcomes found significant by univariate tests as a function of drug exposure and other covariates. We did this by testing the constellation of CNS/ANS outcomes for each infant as repeated binary measures (yes/no) on the same subject and then used generalised estimating equations (GEE) to fit the model and estimate its parameters. ${ }^{33-35}$ This statistical approach avoided the problems with multiple comparisons by fitting a single model to the data. Moreover, since it recognises that all the CNS/ANS outcomes for an infant may be inter-related and together constitute one syndrome, this approach is statistically more efficient than fitting separate models for each outcome. In addition, it allowed for outcome specific exposure effects, and we were able to test whether each specific outcome was affected by exposure to cocaine and/or opiates. In other words, through the statistical modelling, we can derive the odds ratio (OR) for the overall effect of exposure on manifesting the syndrome or constellation of CNS/ANS signs/outcomes as well as the estimated OR for manifesting each individual sign. 
Table 2 Prevalence of CNS/ANS signs

\begin{tabular}{|c|c|c|c|c|c|c|}
\hline CNS/ANS signs & $\begin{array}{l}\text { NON } \\
n=7442 \\
\%\end{array}$ & $\begin{array}{l}\operatorname{EXP} \\
n=1185 \\
\%\end{array}$ & $\begin{array}{l}\text { EXP/NON } \\
\text { Unadjusted OR } \\
(95 \% \mathrm{Cl})^{*}\end{array}$ & $\begin{array}{l}\mathrm{CO} \\
\mathrm{n}=717 \\
\%\end{array}$ & $\begin{array}{l}\text { OP } \\
n=100 \\
\%\end{array}$ & $\begin{array}{l}\mathrm{OP}+\mathrm{CO} \\
\mathrm{n}=92 \\
\%\end{array}$ \\
\hline Jittery, tremors & 5.9 & 16.6 & $3.15(2.5$ to 4.0$)$ & 14.6 & 22.2 & 43.5 \\
\hline Irritability & 5.8 & 14.9 & 2.86 (2.3 to 3.6$)$ & 12.2 & 24.4 & 40.2 \\
\hline High pitched cry & 1.5 & 4.0 & $2.79(1.8$ to 4.4$)$ & 2.8 & 11.4 & 14.9 \\
\hline Hypertonia & 0.8 & 3.2 & 4.27 (2.6 to 7.1$)$ & 2.0 & 7.8 & 9.8 \\
\hline Hyperalertness & 0.1 & 1.3 & $13.10(5.3$ to 32.7$)$ & 0.8 & 1.0 & 5.4 \\
\hline Hyperactive & 0.3 & 1.1 & 4.43 (1.9 to 10.5$)$ & 0.4 & 4.4 & 5.4 \\
\hline Difficult to console & 1.0 & 2.9 & 3.10 (1.8 to 5.2$)$ & 2.0 & 5.6 & 9.8 \\
\hline Difficult to arouse & 0.4 & 1.0 & $2.72(1.2$ to 6.4$)$ & 1.3 & 0 & 1.1 \\
\hline Excessive suck & 0.7 & 3.4 & 5.30 (3.2 to 8.8$)$ & 2.3 & 5.3 & 15.6 \\
\hline Poor suck & 2.7 & 4.4 & 1.65 (1.1 to 2.5$)$ & 3.9 & 4.2 & 4.4 \\
\hline Nasal stuffiness & 1.7 & 3.0 & 1.77 (1.1 to 2.9 ) & 2.7 & 1.0 & 9.8 \\
\hline Sneezing & 3.1 & 4.2 & 1.36 (1.9 to 2.1$)$ & 3.4 & 7.3 & 7.6 \\
\hline Any $\geqslant 1$ signs & 16.6 & 30.7 & 2.23 (1.9 to 2.7$)$ & 28.2 & 44.8 & 62.0 \\
\hline
\end{tabular}

Groups: non-exposed (NON), exposed (EXP), and confirmed cocaine (CO) only, opiates (OP) only, and opiates + cocaine (OP+CO) exposure. The unadjusted OR for EXP/NON with $95 \% \mathrm{Cl}$ are also shown.

${ }^{*}$ All $p$ values $\leqslant 0.05$.

Table 3 Interrelatedness of CNS/ANS signs as expressed by odds ratios

\begin{tabular}{|c|c|c|c|c|c|c|c|c|c|c|c|}
\hline & Irritability & $\begin{array}{l}\text { High } \\
\text { pitched cry }\end{array}$ & Hypertonia & Hyperalert & Hyperactive & $\begin{array}{l}\text { Difficult } \\
\text { to console }\end{array}$ & $\begin{array}{l}\text { Difficult } \\
\text { to arouse }\end{array}$ & $\begin{array}{l}\text { Excessive } \\
\text { suck }\end{array}$ & $\begin{array}{l}\text { Poor } \\
\text { suck }\end{array}$ & $\begin{array}{l}\text { Nasal } \\
\text { stuffiness }\end{array}$ & Sneezing \\
\hline Jitteriness/tremors & $9.3^{*}$ & $11.1^{*}$ & $16.6^{*}$ & $12.8^{*}$ & $12.6^{*}$ & $11.3^{*}$ & 2.0 & $8.5^{*}$ & $4.8 *$ & $5.0^{*}$ & $4.0^{*}$ \\
\hline Irritability & & $27.5^{*}$ & $15.9^{*}$ & $29.6^{*}$ & $27.6^{*}$ & 142.9 * & 1.1 & $17.0^{*}$ & $2.1^{*}$ & $7.4^{*}$ & $2.6^{*}$ \\
\hline High pitched cry & & & $14.8 *$ & 4.7 * & 30.4 * & $31.9 *$ & 1.0 & $15.3^{*}$ & 3.6 * & $3.1^{*}$ & $4.9 *$ \\
\hline Hypertonia & & & & $44.9^{*}$ & $38.4^{*}$ & $27.2^{*}$ & $6.7^{*}$ & $13.2^{*}$ & $7.0 *$ & 0.98 & $7.4^{*}$ \\
\hline Hyperalert & & & & & $76.6 *$ & $36.0 *$ & 6.6 & $52.4^{*}$ & $11.6 *$ & $4.3^{*}$ & 2.5 \\
\hline Hyperactive & & & & & & $58.0^{*}$ & - & $3.3^{*}$ & $18.8^{*}$ & 4.3 & $3.3^{*}$ \\
\hline Difficult to console & & & & & & & & $14.0^{*}$ & $5.1^{*}$ & $6.5^{*}$ & $2.6^{*}$ \\
\hline Difficult to arouse & & & & & & & & 1.8 & $11.6^{*}$ & 1.0 & 2.3 \\
\hline Excessive suck & & & & & & & & & 0.3 & $12.3^{*}$ & $4.0^{*}$ \\
\hline Poor suck & & & & & & & & & & $2.5^{*}$ & $2.9^{*}$ \\
\hline Nasal stuffiness & & & & & & & & & & & $4.8^{*}$ \\
\hline
\end{tabular}

Using the above approach, we first determined the effects of EXP on CNS/ANS outcomes while controlling for confounders. Then another analysis was done to determine specifically the effects of confirmed $\mathrm{CO}$ and OP on outcomes using similar covariates. The covariates chosen for analysis included clinical site, GA, postnatal age at assessment, gender, race, maternal marital status, highest grade of education completed, Medicaid status, prenatal care, sexually transmitted diseases including AIDS/HIV, and use of marijuana, alcohol, and tobacco during pregnancy. Alcohol use and tobacco use were entered into the model with four and three levels, respectively, as obtained from maternal interview at enrolment. Birth weight and other birth measurements were highly correlated with GA and were not included in the multivariate model to avoid colinearity. In the final multivariate models, covariates that were not statistically significant $(\mathrm{p}>0.05)$ were excluded. Adjusted OR (95\% CI) for the constellation of signs as well as for each CNS/ ANS manifestation with each type of exposure (EXP, CO, OP, and $\mathrm{OP}+\mathrm{CO}$ ) were estimated from the multivariate models.

\section{RESULTS}

A total of 19079 mother/infant dyads were screened for study recruitment; 16988 (89\%) met eligibility criteria, and 11811 $(70 \%)$ consented to study participation. From these, adequate meconium was collected in 7442 infants, allowing confirmation of a negative history-that is, non-exposed (NON). There were 3184 whose mothers had denied use, but no or inadequate meconium was collected. Table 1 presents characteristics of this group. Because of unconfirmed non-exposure, these infants were excluded from analysis. A total of 1185 were EXP, of whom 980, 113, and 92, respectively, were exposed to cocaine, opiate, or both. Exposure to CO only, OP only, and OP+CO was confirmed in 717, 100, and 92, respectively. Insufficient or no meconium was collected for confirmation of drug use in the remaining 276.

Of mothers who used opiates during pregnancy, 93\% used heroin and/or methadone. Mothers in the EXP group were significantly older than those in the NON: mean (SD) age of 29.6 (5.1) years compared to 26.1 (5.8) years in the NON. Mothers in the CO only, OP only, and OP+CO groups were also older than NON, having mean (SD) ages, respectively, of 30.1 (4.8), 28.6 (6.4), and 32.4 (5.6) years. Table 1 shows that a higher proportion of mothers in the EXP group were black, not married, with education of $\leqslant 12$ years, with inadequate prenatal care, smoked cigarettes, consumed alcohol, smoked marijuana during pregnancy, and had sexually transmitted diseases, compared to NON. Maternal and infant characteristics of the CO group were similar to EXP. The OP and OP $+\mathrm{CO}$ groups did not differ from NON with regard to race or maternal education. A higher proportion of infants with lower GA and birth weight were seen in all EXP groups compared to NON. Birth length, mean (SD), in EXP was 46.5 (4.7) cm, significantly shorter than 48.9 (4.5) $\mathrm{cm}$ in NON. Mean (SD) head circumference measurements in EXP, CO, OP, and CO+OP were $32.0(2.9), 31.9(2.8), 32.9(3.1)$, and $31.7(3.2) \mathrm{cm}$ respectively, significantly smaller $(\mathrm{p}<0.05)$ compared to 33.4 (2.9) $\mathrm{cm}$ in NON.

Twenty eight per cent of infants were examined for CNS/ANS signs within 24 hours of life, $52 \%$ between 24 and 48 hours, and $12 \%$ between 48 and 72 hours. Mean (SD) postnatal age at assessment was 36 (17) hours. Any CNS/ANS sign was detected in $12 \%$ of those examined in the first 24 hours, and in $18 \%, 17 \%$, 


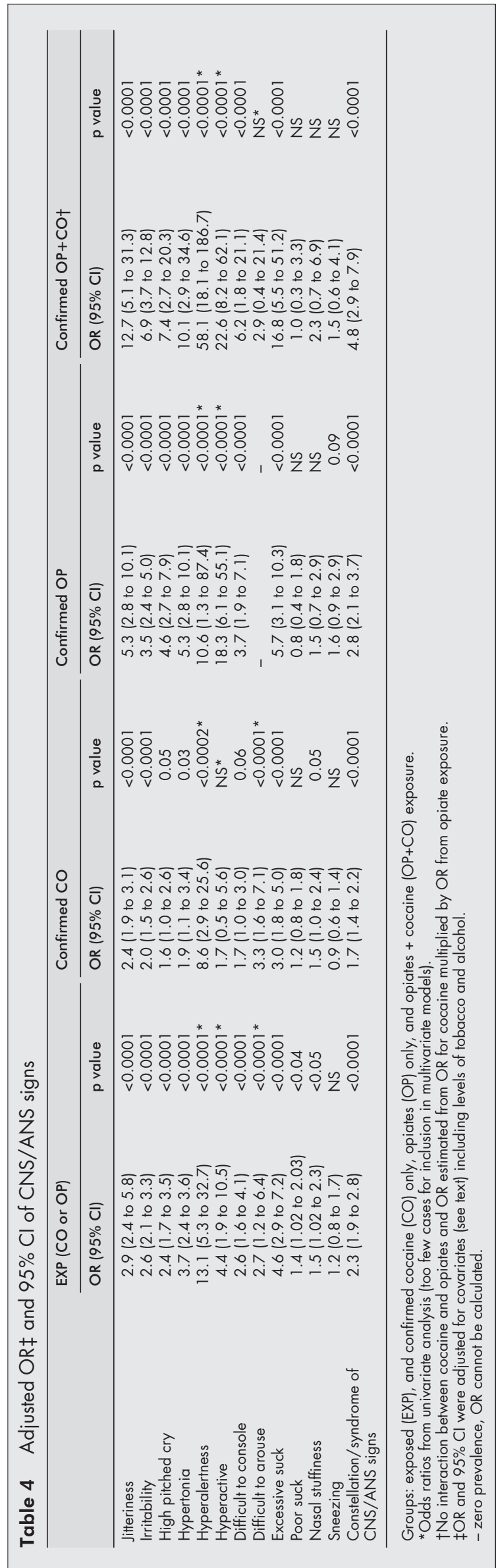

$15 \%$, and $4 \%$ of those examined on the second day, $48-72$ hours, 72-96 hours, and $>96$ hours, respectively.

CNS/ANS signs in any cocaine or opiate exposure (EXP compared to NON)

The prevalence of each of the CNS/ANS signs detected in EXP ranged from $0.1 \%$ to $16.6 \%$. Signs such as abnormal posture, sweating, hiccoughing, bradycardia, hyperthermia, and hypothermia had prevalence of $<0.5 \%$ in EXP. Prevalence of hypotonia, weak cry, lethargy, mottling, tachycardia, and nasal flaring in EXP was between $1.1 \%$ and $2.7 \%$. No gross CNS malformation was seen in EXP. No infant was noted to have seizures during masked assessment. However, on medical record review, three infants (one in OP and two in $\mathrm{OP}+\mathrm{CO}$ ) had seizures as a manifestation of drug withdrawal. Table 2 shows the signs found to be statistically of higher proportion $(p<0.05)$ in EXP and are summarised by estimated OR (95\% CI). Of signs significantly associated with drug exposure, the most prevalent were CNS signs-that is, jitteriness/tremors and irritability observed at rates of $16.6 \%$ and $14.9 \%$, respectively. Hypertonia and high pitched cry were observed in 3.2\% and $4 \%$ of EXP. These CNS/ANS signs were also significantly interrelated as shown in table 3. Thus an infant with jitteriness/tremors was 16.6 times more likely to manifest with hypertonia, 9.3 times more likely to be irritable, 11.3 times more likely to have high pitched cry, 5 times more likely to have nasal stuffiness, and 8.5 times more likely to have excessive suck.

In the multivariate analysis the signs hyperactivity, hyperalertness, and difficult to arouse were not included in the model because few babies had these signs. Table 4 shows the results of the multivariate analysis. This table shows the adjusted OR (95\% CI) for the outcome of manifesting the constellation or syndrome of CNS/ANS outcomes and for each CNS/ANS sign associated with being in the EXP group. Any drug exposure (that is, EXP) was significantly associated with the constellation of CNS/ANS outcomes, OR (95\% CI): 2.34 (1.92 to 2.84), $\mathrm{p}<0.0001$. EXP infants were two to three times more likely to exhibit jitteriness/tremors, irritability, hypertonia, high pitched cry, or difficult to console; they were also greater than four times more likely to have excessive suck, and one and one half times more likely to show poor suck and nasal stuffiness. We found significant site differences, but GA, postnatal age at assessment, race, gender, or sexually transmitted diseases did not significantly influence CNS/ANS outcomes. Neither alcohol nor marijuana had effects on outcomes. However, smoking had an independent effect on the syndrome of CNS/ANS outcomes. Odds ratios (95\% CI) for manifesting the constellation of CNS/ANS signs when a mother smoked less than half a pack a day, and half a pack or more a day were, respectively, 1.2 (0.99 to 1.45), $\mathrm{p}<0.07$ and 1.4 ( 1.2 to 1.6$), \mathrm{p}<0.0002$.

\section{CNS/ANS signs in confirmed $\mathrm{CO}$ and OP exposure}

Table 2 also shows the prevalence of CNS/ANS signs in confirmed CO only, OP only, and OP+CO exposure. In CO, jitteriness/tremors and irritability were at rates of $14.6 \%$ and $12.2 \%$, respectively. All other signs occurred in less than $5 \%$ of babies. The presence of at least one sign, however, occurred in $28.2 \%$ of infants with CO only exposure. In OP, prevalence of most of the CNS/ANS signs was higher than observed in CO. Jitteriness/tremors and irritability were manifested in $22 \%$ and $24 \%$, respectively, of OP infants. Any $\geqslant 1$ sign was observed in $44.8 \%$ of those with confirmed exposure to OP only and in $62 \%$ of those exposed to OP+CO. Except for difficult to arouse, the prevalence of CNS/ANS signs in $\mathrm{OP}+\mathrm{CO}$ exposure increased above those observed in OP or CO infants. Difficult to arouse was a sign significant only in CO infants. After controlling for confounders, $\mathrm{CO}$ and OP exposed infants were more likely than NON to manifest the constellation of CNS/ANS signs with OR (95\% CI), respectively, of 1.7 ( 1.4 to 2.2 ), $\mathrm{p}<0.0001$ and 2.8 (2.1 to 3.7), $\mathrm{p}<0.0001$. We found no 
interaction between cocaine and opiate use. With $\mathrm{CO}$ and OP having independent effects, exposure to $\mathrm{OP}+\mathrm{CO}$ increased the risk for CNS/ANS manifestations, OR (95\% CI) of 4.8 (2.9 to $7.9), \mathrm{p}<0.0001$. Of outcomes analysed, we found each of the CNS signs, jitteriness/tremors, irritability, hypertonia, difficult to console, and high pitched cry to be highly associated with exposure, whether this be $\mathrm{CO}$ or OP or both.

The signs, poor suck, nasal stuffiness, and sneezing individually were not significantly associated with either CO or OP after controlling for confounders. It must be stressed, however, that these signs were significantly related to signs found to be individually significant and were in the model as components of the syndrome or constellation of CNS/ANS outcomes, the overall outcome tested for cocaine and opiate effects.

With confirmed CO and OP exposure in the model, the other variables with significant effects on outcome were clinical site and smoking. The OR (95\% CI) for manifesting the constellation of the CNS/ANS outcomes with smoking less than half a pack of cigarettes a day, and half a pack or more a day were, respectively, 1.27 ( 1.04 to 1.55 ), $\mathrm{p}<0.02$ and 1.4 ( 1.20 to 1.60$), p<0.0003$. No other factors were significantly associated with CNS/ANS outcomes.

\section{DISCUSSION}

Clinicians evaluate neonates for withdrawal manifestations through routine physical and neurological examination or by Finnegan's Neonatal Abstinence Scoring System, ${ }^{30}$ especially when progression and severity of manifestations are being assessed. Other studies have used the Neonatal Withdrawal Inventory, ${ }^{36}$ the Brazelton's Neonatal Behavior Assessment Scales (NBAS), ${ }^{21}$ or the NICU Network Neurobehavioral Scale (NNNS), ${ }^{31}$ with measures derived from the NBAS, but modified specifically to evaluate drug exposed infants and other high risk populations. Although we evaluated enrolled infants for CNS/ANS signs described in Finnegan's Neonatal Abstinence Scoring System, ${ }^{30}$ no attempt was made to obtain abstinence scores. It was our main intent at the onset to establish whether these signs would even be evident among exposed infants, especially with an evaluation performed masked to infants' exposure status. Furthermore, enrolment of a large number of term infants and early discharge practice in participating centres precluded repeated assessment and use of a more intensive evaluation such as the NBAS. ${ }^{19} 2037$

We found a low prevalence of CNS/ANS signs but significantly higher in the EXP group, which included a large number of cocaine exposed infants. The prevalence of signs was almost double in opiate only exposure but lower than reported rates in heroin ${ }^{5638} 39$ and methadone exposure..$^{6-84041}$ Variation in reported incidence of CNS/ANS signs may be related to different factors, such as dose, duration of addiction, and time interval between last dose and delivery. ${ }^{38}{ }^{42}$ However, our study was not designed specifically to investigate the relation between CNS/ANS signs and these factors.

Lower overall prevalence of CNS/ANS signs in our study may also be attributed to postnatal age at assessment of infants enrolled. As onset of withdrawal signs correlates inversely with time interval between last dose and delivery, ${ }^{3}$ we may have missed detection of CNS/ANS signs with onset at later postnatal ages. Although we controlled for postnatal age at assessment in our analysis, the short nursery stay of our infants was a major limitation in detecting the true prevalence of CNS/ANS signs following in utero drug exposure. Furthermore, onset of withdrawal manifestations, especially in methadone exposure, may be delayed, as late as 4 weeks. ${ }^{9}$ Our findings therefore are likely underestimates of the true prevalence of CNS/ANS signs following CO or OP exposure. In a full term cohort, Tronick and colleagues ${ }^{43}$ found no neurobehavioural effects of cocaine exposure at 2-3 days of age after controlling for confounders. It was not until 3 weeks of age that heavy exposure to cocaine was significantly associated with poorer state regulation and greater excitability. Studies by Chiriboga and colleagues 2234 showed high prevalence of neurological abnormalities in cocaine exposed infants; their infants were examined at later postnatal ages compared to our infants. Coles and colleagues ${ }^{45}$ found little evidence of "classic" withdrawal signs in cocaine exposed babies. Richardson and colleagues ${ }^{46}$ observed autonomic instability associated with in utero cocaine exposure at 2 days postnatal age, regardless of trimester exposure, but findings were transient and were not observed at age 3 days.

A review by Lester and colleagues ${ }^{47}$ highlighted the conflicting reports on neonatal effects of in utero cocaine exposure. In addition to variation in methods of assessment of CNS/ANS signs, differences in observed effects among studies may be attributed to small sample size, failure to control for multiple variables, and variation in subject selection secondary to methods of identification of exposure and confirmation of negative status among selected controls. Inaccuracy and poor recall inherent in maternal self report of drug use, ${ }^{48}$ low sensitivity and specificity of urine drug screening methods, ${ }^{49}$ and unmasked evaluation of infants might result in bias in selection of study and comparison groups..$^{50}$

We placed a major effort in our study design to improve on weaknesses evident in previous studies. Our findings were derived from a large sample. We also confirmed drug exposure using GC/MS of meconium samples, a superior method to urine RIA screening. ${ }^{49}$ Furthermore, to minimise bias, infants enrolled were evaluated by research personnel masked to infants' exposure status. In spite of a lower prevalence of CNS/ ANS signs than in other reports, we did find that cocaine exposure was associated with increased likelihood of manifesting a constellation of CNS/ANS signs, an effect independent of opiate exposure. ${ }^{19} 2151-53$ Infants with confirmed CO exposure were more likely to have jitteriness/tremors, irritability, hypertonia, high pitched cry, and were difficult to console, findings consistent with the reports by Chiriboga and colleagues $^{22} 2344$ and Tsay and colleagues. ${ }^{54}$

The variable fetal or neonatal effects of cocaine may be explained by pharmacological factors ${ }^{39}{ }^{51-57}$ : individual differences in drug metabolism, high potential for cocaine in traversing biological membranes but with slow tissue biotransformation, variability in plasma elimination half life, the potency and unpredictable vascular effects of both active and inactive cocaine metabolites, and variability of cocaine effects on receptor densities or binding. Signs in cocaine exposed babies may be secondary effects-that is, resulting from hypoxaemia, growth retardation, and/or poor nutrition, ${ }^{56-58}$ as a result of the vasoconstrictive effect of cocaine on placental vessels, and thus the unpredictability of correlation between plasma cocaine concentration and prevalence or severity of withdrawal manifestations. Of interest is the reported dose-response effect of cocaine on neonatal neurobehavioural performance ${ }^{59}$; amount of cocaine use was carefully deduced from maternal self report. ${ }^{59}$ A dose-response effect of cocaine exposure on neurological findings was also reported in infants $>36$ weeks gestation. ${ }^{44}$ Higher likelihood of hypertonia occurred with higher levels of cocaine detected by RIA in maternal hair. ${ }^{44}$ We were unable to address dose-exposure effect of cocaine at this phase of the study, but a subpopulation is enrolled in long term developmental follow up, with planned neurobehavioural evaluation at 42-45 weeks postconceptional age and a detailed maternal interview of drug use. This may permit exploration of relations between CNS/ANS manifestations and dose.

Maternal polydrug use has been reported to result in more frequent and more severe neonatal withdrawal signs than single drug use..$^{356061}$ Mayes and Carroll ${ }^{62}$ observed higher withdrawal scores in infants exposed to both cocaine and methadone compared to those with no added exposure to cocaine. In our study, the effects of exposure to the combination of opiate and cocaine were additive. In animal studies, 
cocaine increases opiate receptor binding, therefore enhancing opiate effects. ${ }^{63}{ }^{64}$ Thus, in maternal opiate plus cocaine abuse, disappearance of opiates after birth may increase the likelihood of development of neonatal withdrawal manifestations than with exposure to opiate only. Furthermore, the combined effects of opiate and cocaine on the upregulation of cAMP have been associated with increase in glutaminergic and noradrenergic responses. ${ }^{64}$ Increased glutaminergic activity may explain observed manifestations such as irritability, excitability, or tremors after cocaine or opiate exposure.

Dempsey and colleagues ${ }^{65}$ observed that tone abnormalities are predicted by neonatal urine cotinine levels rather than concentrations of cocaine metabolites in meconium and urine. Prenatal exposure to cigarettes has been associated with measurable neurobehavioural effects. ${ }^{66}$ Studies have also alluded to the resemblance between cocaine and nicotine effects. ${ }^{67}$ We found a significant association between smoking and CNS/ANS outcomes independent of drug effects. As a large proportion of women who use cocaine also smoke during pregnancy, future studies will need to evaluate neonatal and long term effects in the context of exposure to both substances.

In summary, the large number of exposed infants in our study has enabled us to discriminate effects related to cocaine from those of opiates, while taking into consideration multiple confounding variables. In utero cocaine exposure is significantly associated with manifesting a constellation of CNS/ANS outcomes. CNS signs are the more prevalent manifestations, but these are significantly interrelated to one another and to ANS signs. These manifestations are similar to signs of opiate withdrawal. However, it remains unclear whether these signs associated with cocaine exposure are withdrawal signs or rather manifestations of toxic effects of cocaine on the developing fetal brain. Perhaps, exploring any relation between these manifestations and early gestational cocaine exposure as detected by neonatal hair analysis ${ }^{68}$ may help assess whether these signs relate to withdrawal or drug effects. Furthermore, long term follow up of these children will be needed to determine the prognostic significance of these early CNS signs. The association between cocaine exposure and CNS/ANS outcomes, the additive effects associated with exposure to both cocaine and opiate, the reported subacute manifestations in narcotic withdrawal, and possibility of late onset manifestations in either cocaine and opiates exposure must prompt primary care providers for early and frequent postdischarge health monitoring of these high risk infants.

\section{ACKNOWLEDGEMENTS}

Supported by the National Institute of Child Health and Human Development through cooperative agreements: U10 HD 27856, U10 HD 21397, U10 HD 21385, U10 HD 27904, and U01 HD 36790, as well as interagency agreements with the National Institute on Drug Abuse (NIDA), Administration on Children, Youth and Families (ACYF), and Center for Substance Abuse Treatment (CSAT).

\section{Authors' affiliations}

H S Bada, University of Kentucky, Department of Pediatrics, Lexington, KY, USA

C R Baver, University of Miami School of Medicine, Department of Pediatrics, Miami, FL, USA

S Shankaran, Wayne State University School of Medicine, Department of Pediatrics, Detroit, MI, USA

B Lester, Brown University School of Medicine, Department of Pediatrics, Women's and Infants Hospital, Providence, RI, USA

L L Wright National Institute of Child Health and Human Development (NICHD), Bethesda, MD, USA

A Das, K Poole, Research Triangle Institute, Research Triangle Park, NC, USA

V L Smeriglio, National Institute on Drug Abuse (NIDA), Bethesda, MD, USA

L P Finnegan, Office of Research on Women's Health, National Institutes of Health, Bethesda, MD, USA

P L Maza, Administration of Children, Youth and Families (ACYF), Washington, DC, USA

\section{REFERENCES}

1 Rothstein P, Gould JB. Born with a habit, infants of drug addicted mothers. Pediatr Clin North Am 1974:21:307-21.

2 Roberts RJ. Fetal and infant intoxication. In: Drug therapy in infants: pharmacologic principles and clinical experience. Philadelphia: WB Saunders, 1984:322-83.

3 Rosen TS, Pippenger CE. Pharmacologic observations on the neonatal withdrawal syndrome. J Pediatr 1976;88:1044-8.

4 Schulman CA. Alterations of the sleep cycle in heroin-addicted and "suspect" newborns. Neuropediatrics 1969;1:89-100.

5 Zelson C, Rubio E, Wasserman E. Prenatal narcotic addiction 10 year observation. Pediatrics 1971;48:178-89.

6 Zelson C, Lee SJ, Casalino M. Neonatal narcotic addiction: comparative effects on maternal intake of heroin and methadone. N Engl J Med 1973;289:1216-20.

7 Rajegowda BK, Glass L, Evans HE, et al. Methadone withdrawal in newborn infants. J Pediatr 1972;81:532-4.

8 Wilson GS, Desmond MM, Verniaud WM. Early development of infants of heroin-addicted mothers. Am J Dis Child 1973;126:457-62.

9 Kandall SR, Gartner LM. Late presentation of drug withdrawal symptoms in newborns. Am J Dis Child 1974;127:58-61.

10 Preis O, Choi SJ, Rudolph N. Pentazocine withdrawal syndrome in the newborn infant. Am J Obstet Gynecol 1977;127:205-6.

11 Prenner BM. Neonatal withdrawal syndrome associated with hydroxyzine hydrochloride. Am J Dis Child 1977;131:529-30.

12 Tyson HK. Neonatal withdrawal symptoms associated with maternal use of propoxyphene hydrochloride (Darvon). J Pediatr 1974;85:684-5.

13 Webster PAC. Withdrawal symptoms in neonates associated with maternal antidepressant therapy. Lancet 1973;2:318-19.

14 Neuspiel DR, Hamel SC. Cocaine and infant behavior. Dev Behav Pediatr 1991; 12:55-64.

15 Young SL, Vosper HJ, Phillips SA. Cocaine, its effects on maternal and child health. Pharmacotherapy 1992;12:2-17.

16 Madden JD, Payne TF, Miller S. Maternal cocaine abuse and effect on the newborn. Pediatrics 1986;77:209-21.

17 Hadeed AJ, Siegel SR. Maternal cocaine use during pregnancy: effect on the newborn infant. Pediatrics 1989;84:205-10.

18 Cherukuri R, Minkoff H, Feldman J, et al. A cohort study of alkaloid cocaine ("crack") in pregnancy. Obstet Gynecol 1988;72:147-51.

19 Chasnoff IJ, Burns WJ, Schnoll SH, et al. Cocaine use in pregnancy. N Engl J Med 1995;313:666-9.

20 Oro AS, Dixon SD. Perinatal cocaine and methamphetamine exposure: maternal and neonatal correlates. J Pediatr 1987;111:571-8.

21 Napiorkowski B, Lester BM, Freier C, et al. Effects of in utero substance exposure on infant neurobehavior. Pediatrics 1996:98:71-5.

22 Chiriboga CA, Bateman DA, Brust JCM, et al. Neurologic findings in neonates with intrauterine cocaine exposure. Pediatr Neurol 1993;9:115-19.

23 Chiriboga CA, Vibbert M, Malouf R, et al. Neurological correlates of fetal cocaine exposure: transient hypertonia of infancy and childhood. Pediatrics 1995;96:1070-7

24 Doberczak TM, Shanzer S, Senie RT, et al. Neonatal neurologic and electroencephalographic effects of intrauterine cocaine exposure. $J$ Pediatr 1988; 113:354-8.

25 Kramer LD, Locke GE, Ogunyemi A, et al. Neonatal cocaine-related seizures. J Child Neurol 1990;5:60-4.

26 Dixon SD, Bejar R. Echoencephalographic findings in neonates associated with maternal cocaine and methamphetamine use: incidence and clinical correlates. J Pediatr 1989;115:770-8

27 Heier LA, Carpanzano CR, Mast J, et al. Maternal cocaine abuse: the spectrum of radiologic abnormalities in the neonatal CNS. AJNR $1991 ; 12: 951-6$

28 Baver CR, Shankaran S, Bada HB, et al. The maternal lifestyle study (MLS): drug exposure during pregnancy and short-term materna outcomes. Am J Obstet Gynecol. 2002;186:487-95.

29 Ballard JL, Khoury JC, Wedig K, et al. New Ballard score, expanded to include extremely premature infants. J Pediatr 1991;119:417-23.

30 Finnegan LP. Neonatal abstinence. In Nelson NM, ed. Current therapy in neonatal perinatal medicine. Toronto, Philadelphia: B. C. Decker, Inc. 1985:262-70.

31 Brazelton TB, Nugent JK. In: Neonatal Behavior Assessment Scale, 3rd edn. Clin Dev Med No. 137. London: MacKeith Press, 1995.

32 EISohly MA, Stanford DF, Murphy TP, et al. Immunoassay and GC-MS procedures for the analysis of drugs of abuse in meconium. J Anal Toxicol 1999:23:436-45.

33 Fitzmaurice GM, Laird NM, Zahner GE, et al. Bivariate logistic regression analysis of childhood psychopathology ratings using multiple informants. Am J Eipdemiol 1995;142:1194-203.

34 Legler J, Lefkopoulou M, Ryan L. Efficiency and power of tests for multiple binary outcomes. J Am Stat Assoc 1995;90:680-93.

35 Liang KY, Zeger SL. Longitudinal data analysis using generalized linear models. Biometrika 986;73:13-22.

36 Zahorodny W, Rom C, Whitney W, et al. The Neonatal Withdrawal Inventory: a simplified score of newborn withdrawal. Dev Behav Pediatr 1998; 19:89-93.

37 Eyler FD, Behnke $M$, Conlon $M$, et al. Birth outcome from a prospective, matched study of prenatal crack/cocaine use: II. Interactive and dose effects on neurobehavioral assessment. Pediatrics 1998;101:2137-41.

38 Fricker HS, Segal S. Narcotic addiction, pregnancy, and the newborn. Am J Dis Child 1978;132:360-6.

39 Ostrea EM, Chavez CJ, Strauss ME. A study of factors that influence the severity of neonatal narcotic withdrawal. J Pediatr 1976;88:642-5. 
40 Wilson GS, Desmond MM, Wait RB. Follow-up of methadone-treated and untreated narcotic-dependent women and their infants: health developmental, and social implications. J Pediatr 1981;98:716-22.

41 Van Baar AL, Fleury P, Soepatmi S, et al. Neonatal behaviour after drug dependent pregnancy. Arch Dis Child 1989;64:235-40.

42 Farrar HC, Kearns GL. Cocaine: clinical pharmacology and toxicology J Pediatr 1989;115:665-75.

43 Tronick EZ, Frank DA, Cabral H, et al. Late dose-response effects of prenatal cocaine exposure on newborn neurobehavioral performance. Pediatrics 1996:98:76-83.

44 Chiriboga CA, Brust JCM, Bateman D, et al. Dose-response effect of fetal cocaine exposure on newborn neurologic function. Pediatrics 1999; 103:79-85.

45 Coles CD, Platzman KA, Smith I, et al. Effects of cocaine and alcohol use in pregnancy on neonatal growth and neurobehavioral status. Neurotoxicol Teratol 1992;14:23-33.

46 Richardson GA, Hamel SC, Goldschmidt L, et al. The effects or prenata cocaine use on neonatal neurobehavioral status. Neurotoxicol Teratol 1996; 18:519-28.

47 Lester BM, LaGasse L, Brunner S. Data base of studies on prenatal cocaine exposure and child outcome. J Drug Issues 1997;27:487-99.

48 Zuckerman B, Amaro H, Cabral H. Validity of self-reporting of marijuana and cocaine use among pregnant adolescents. J Pediatr 1989;115:812-15.

49 Ostrea EM. Testing for exposure to illicit drugs and other agents in the neonate: a review of laboratory methods and the role of meconium analysis. Curr Probl Pediatr February 1999:41-56.

50 Woods NS, Eyler FD, Conlon M, et al. Pygmalion in the cradle: observer bias against cocaine-exposed infants. J Dev Behav Pediatr 1998:19:283-5.

51 Fulroth R, Phillips B, Durand DJ. Perinatal outcome of infants exposed to cocaine and/or heroin in utero. Am J Dis Child 1989;143:905-10.

52 LeBlanc PE, Parekh AJ, Glass L. Effect of intrauterine exposure to alkaloid cocaine ("crack"). Am J Dis Child 1987;141:937-8.

53 Datta-Bhutada S, Johnson HL, Rosen TS. Intrauterine cocaine and crack exposure: neonatal outcome. J Perinatol 1998;18:183-8.

54 Tsay CH, Partridge JC, Villarreal SF, et al. Neurologic and ophthalmologic findings in children exposed to cocaine in utero. J Child Neurol 1996:11:25-30.
55 Wiggins RC. Pharmacokinetics of cocaine in pregnancy and effects of fetal maturation. Clin Pharmacokinet 1992;22:85-93.

56 Pane MA, Traystman RJ, Gleason CA. Ecgonine methyl ester, a majo cocaine metabolite, causes cerebral vasodilation in neonatal sheep. Pediatr Res 1997;41:815-21.

57 Lester BM, Corwin M, Sepkoski C, et al. Neurobehavioral syndromes in cocaine-exposed newborn infants. Child Dev 1991;62:694-705.

58 Zuckerman B, Frank DA, Hingson R, et al. Effects of maternal marijuana and cocaine use on fetal growth. N Engl J Med 1989;320:762-8.

59 Martin JC, Barr HM, Martin DC, et al. Neonatal neurobehavioral outcome following prenatal exposure to cocaine. Neurotoxicol Teratol 1996; 18:617-25

60 Neerhof MG, MacGregor SN, Retzky SS, et al. Cocaine abuse during pregnancy: peripartum prevalence and perinatal outcome. Can J Obstet Gynecol 1989;161:633-8.

61 Bingol N, Fuchs $M$, Diaz V, et al. Teratogenicity of cocaine in humans. J Pediatr 1987;110:93-6.

62 Mayes LC, Carroll KM. Neonatal withdrawal syndrome in infants exposed to cocaine and methadone. Substance Use \& Misuse 1996;31:241-53.

63 Spear LP, Heyser CJ. Cocaine and the developing nervous system: laboratory findings. In: Zagon IS, Slotkin TA, eds. Maternal substance abuse and the developing nervous system. San Diego, CA: Academic Press, Inc., 1992: 155-75.

64 Nestler EJ, Aghajanian GK. Molecular and cellular basis of addiction. Science 1997;278:58-63

65 Dempsey DA, Hajnal BL, Partridge C, et al. Tone abnormalities are associated with maternal cigarette smoking during pregnancy in in utero cocaine-exposed infants. Pediatrics 2000;106:79-85.

66 Fried PA. Cigarettes and marijuana: are there measurable long-term neurobehavioral teratogenic effects? Neurotoxicology 1989;10:577-84

67 Slotkin TA. Fetal nicotine or cocaine exposure: which one is worse? J Pharmacol Exp Ther 1988;285:931-45.

68 Katikaneni LD, Sallee FR, Hulsey TC. Neonatal hair analysis for benzyolecgonine: a sensitive and semi-quantitative biological marker of chronic gestational cocaine exposure. Biol Neonate 2002;81:29-37.

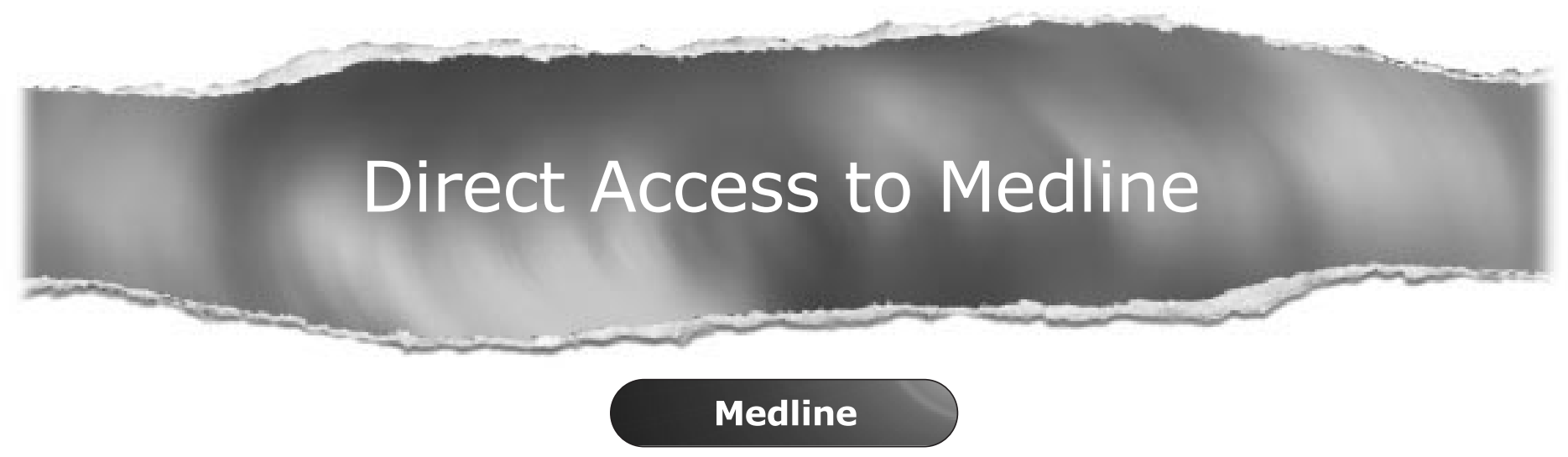

Link to Medline from the homepage and get straight into the National Library of Medicine's premier bibliographic database. Medline allows you to search across 9 million records of bibliographic citations and author abstracts from approximately 3,900 current biomedical journals.

\section{www.archdischild.com}

